\title{
RÉPLICA
}

\section{LA GLOBALIZACIÓN TEMPRANA. RÉPLICA A MARIANO BONIALIAN}

\author{
Bernd Hausberger \\ El Colegio de México
}

$S_{\text {pase desapercibido. Se podría pensar que lo óptimo es que el }}^{\text {i alguien publica un libro, lo peor que puede sucederle es que }}$ texto reciba muchos elogios. Pero, por lo menos a mí, me anima mucho más que mis propuestas estimulen el debate. De esta suerte, siento un enorme gusto que Mariano Bonialian se haya tomado el tiempo para escribir varias páginas sobre mi reciente libro Historia minima de la globalización temprana (El Colegio de México, 2018), y tanto más porque es un autor que se ha distinguido por sus importantes aportes a la temática sobre la que también versa mi tomo. ${ }^{1}$ Bonialian encuentra muchos méritos en mi texto (de los que en parte no me había dado cuenta), señala algunas deficiencias y omisiones (en lo que básicamente le doy la razón), y abre el debate sobre una de las hipótesis centrales que he formulado acerca del papel de la América hispánica en desarrollo que denomino la globalización temprana.

Hay que resumir brevemente el argumento. ${ }^{1}$ Sostengo que la globalización temprana entre los siglos XVI y XIX se desplegó en

\footnotetext{
${ }^{1}$ Había desarrollado estas ideas anteriormente en otros lugares, sobre todo en "Consideraciones acerca del papel de América Latina para el arranque de
} 
una dinámica multipolar a partir de la expansión ibérica al Nuevo Mundo. Sus bases económicas las formaron la producción manufacturera de Eurasia y los metales preciosos de América. Los europeos desempeñaron en este sistema, en primer lugar, una función intermediaria entre los productos asiáticos y los metales preciosos americanos. Las ganancias que obtuvieron, sin embargo, fueron considerables. ${ }^{2}$ La América española con los envíos de plata ( $y$ en menor medida, de oro, el que, entre finales del siglo xvir y finales del xviII, constituiría la riqueza de Brasil) sostuvo los circuitos transcontinentales del comercio, así como las estructuras administrativas y fiscales de los imperios, en fin, los vínculos que enlazaron de modo sostenido las diferentes regiones del globo en la época investigada.

Hasta aquí Bonialian parece que está de acuerdo conmigo. Lo que cuestiona es el rango protagónico que atribuyo a la América española y la explicación que doy a los flujos de metales preciosos, explicación que para mí, como Bonialian está bien consciente (p. 800), resulta esencial para poder hablar de Hispanoamérica como uno de los polos de la globalización temprana. Es importante destacar que parto de un enfoque centrado en actores y sus prácticas, lo que Bonialian quizá no toma suficientemente en cuenta. Voy a plantear la idea un poco más ampliamente. El punto de partida de mi argumentación es que las aspiraciones originales de Colón, de llegar por la ruta occidental directamente a China y acaparar parte de la lucrativa importación europea de los productos asiáticos, se vieron frustradas por las realidades indianas. A los primeros españoles en el Nuevo Mundo, en ese momento, les era imposible enriquecerse mediante la reventa

la globalización”, en Carlos Riojas y Stefan Rinke (coords.), Historia global. Perspectivas y tensiones, Stuttgart, Verlag Hans-Dieter Heinz, Akademischer Verlag, 2017, pp. 55-76.

2 Hausberger, Historia minima, p. 235. Sólo en las décadas finales del siglo xviII, pero sobre todo en el siglo xIx la industrialización europea cambiaría este panorama. 
de productos americanos en Europa (e igualmente mediante la reventa de productos eurasiáticos en América). Por ello, y sin abandonar sus anhelos de volverse ricos y ascender socialmente, intentaron resolver la situación mediante la conquista y el saqueo. Pero el oro acumulado por las culturas prehispánicas sólo enriqueció a unos cuantos y se agotó demasiado rápido, y el tributo que se extrajo de la población sometida tampoco aportó riqueza duradera. Así se afrontaba la necesidad de buscar otra forma de beneficio que pudieran sacar del Nuevo Mundo.

Es crucial tener en cuenta que las aspiraciones de los españoles sólo se podían satisfacer dentro de los parámetros culturales que llevaban consigo. Pretendían ser señores a la usanza europea. Nunca pensaron en adaptar su cultura material y simbólica a las costumbres indígenas (si bien cierto mestizaje, por ejemplo, en el campo de la alimentación, era inevitable). No ambicionaban acumular plumas de quetzal, piedras de jade o turquesas, sino telas italianas o asiáticas, vino español, especies orientales u objetos de vidrio; querían celebrar las misas en iglesias adornadas con lienzos al óleo, y necesitaban armas de hierro y de fuego. Por consiguiente, tanto su riqueza y su estatus como su seguridad dependían de los bienes traídos del Viejo Mundo; y desde el principio la América conquistada engendró una demanda de productos de importación que sólo pudo ser satisfecha por el comercio transoceánico. Así sucedió que, no obstante, la revitalización de los valores señoriales en el contexto de la conquista, el comercio mantuvo su importancia crucial. Para adquirir los productos de importación requeridos se necesitaba con qué intercambiar, es decir, para poder importar, fue imprescindible exportar (o hacerse de dinero de otra manera, pero esta otra manera no se presentó). Como las sociedades americanas no disponían de suficientes productos exportables, los españoles se vieron forzados a promover con urgencia una producción destinada a los mercados externos. La solución se les ofreció en forma de abundantes yacimientos de 
metales preciosos, y fue sobre todo la producción de la plata a gran escala lo que le permitió a la nueva élite de los territorios conquistados mantener, fortalecer y reproducir su rango social y su correspondiente habitus y cultura. De esta forma, produjeron la "mercancía dinero"3 que no podían obtener con el comercio. A partir de ahí, la plata pasaría a ser la mercancía más importante de exportación hispanoamericana. Sólo poco a poco se pudieron organizar otros productos para la exportación, como el tabaco, tintes como el añil o la cochinilla, cueros y azúcar, los que, sin embargo, nunca pudieron competir con la plata como el producto de exportación más importante.

Para evitar malentendidos, hay que subrayar que el nuevo sector minero nunca funcionó como un enclave, desde el cual se organizara el directo intercambio metales-productos de importación. La explotación de las vetas estaba inserta en lo que Carlos Sempat Assadourian ha llamado el sistema de la economía colonial. ${ }^{4}$ Con sus efectos de arrastre estimuló una dinámica producción interna y la reorganización del espacio, en el que gran parte de la plata circulaba antes de salir a los circuitos externos. Pero esto no afecta mi argumento. Sostengo que tuvo que circular para introducir toda la fuerza de compra del espacio colonial (análogamente al otro lado del Atlántico, la plata circulaba por el continente europeo antes de seguir su camino hacia el sur y este de Asia).

A esta interpretación, que atribuye una función central a los intereses de consumo de los españoles, Bonialian le opone principalmente tres argumentos, relacionados entre sí. Cuestiona si

\footnotetext{
3 Carlos Sempat Assadourian, "La producción de la mercancía dinero en la formación del mercado interno colonial”, en Enrique Florescano (ed.), Ensayos sobre el desarrollo económico de México y América Latina (1500-1975), México, Fondo de Cultura Económico, 1979, pp. 223-292.

${ }^{4}$ Carlos Sempat Assadourian, El sistema de la economía colonial. Mercado interno, regiones y espacio económico, Lima, Instituto de Estudios Peruanos, 1982.
} 
el uso de una categoría como el consumo no resulta anacrónico para la época estudiada (p. 799). Ahora, si el término sugiere alguna noción de una "sociedad de consumo" como hoy en día la conocemos, está totalmente fuera de mis intenciones. Uso el término sin implicaciones teóricas, para describir la práctica de usar (y querer usar) productos específicos (ponerse ropas, beber vino, etc.). Para ello no se me ocurre mejor palabra.

Bonialian, además, sostiene que sobrestimo la fuerza de compra del mercado hispanoamericano, en realidad reducido a unas pocas ciudades no muy grandes y a un estrecho sector de notables españoles; opina que antes de proponer mi hipótesis, "hubiese sido sugerente detenerse en la relación consumo/ población para ponderar la valoración de la variable consumo en ese momento histórico" (p. 799). Ahora, es verdad que en la América española de aquella época no vivían tantos consumidores de productos de importación, aunque habría que tomar en cuenta que pronto también parte de la población indígena y de las castas estimaron, por ejemplo, las herramientas de hierro y también aspiraron a adquirir bienes de prestigio, aunque sólo fuera para adornar sus iglesias y sus fiestas. Con todo, el mercado hispanoamericano era pequeño, en comparación con los europeos o asiáticos. No obstante, sigo creyendo que fue suficientemente grande, y lo que me hace creerlo es que la mayor parte de la plata salía de América movida por el comercio privado. He presentado números más detallados en mi libro, ${ }^{5}$ y me parecen datos difícilmente de pasar por alto. El comercio envió estos metales en su aplastante mayoría como paga de las importaciones. Éstas se compraban en América para su uso (consumo), no para almacenarlas y menos para dejarlas echar a perder.

En suma, me sigue pareciendo defendible suponer que fueron principalmente los intereses minero-mercantiles

${ }^{5}$ Hausberger, Historia minima, pp. 132-133. 
hispanoamericanos los que incorporaban los metales preciosos a los circuitos internacionales, movidos por su demanda de productos importados de Eurasia. Obviamente, la exportación masiva de metales preciosos de América benefició a la corona española y a los comerciantes andaluces, así como a la administración y la economía del imperio chino. Pero igualmente obvio es que no fue la voluntad del rey de España o del emperador de China, ni tampoco de los banqueros de Génova, Augsburgo, Ámsterdam o Londres, la que hizo fluir los metales. Los monarcas sólo pudieron fomentar, pero no gestionar la producción, y menos aún tal gestión estuvo en manos de los chinos y, antes del siglo XIX, tampoco de los capitalistas británicos.

La tercera objeción de Bonialian es más fundamental. Alega que doy una explicación demasiado estrecha a los flujos de los metales preciosos al no tomar en cuenta de manera plena el contexto en que se inscribe; siente que subestime "en gran medida, el papel de las políticas metropolitanas españolas. Valdría recordar la política mercantilista que reinaba por entonces en los estados europeos, donde la concentración de metales preciosos hacía a la grandeza del reino [...]. Creemos que el surgimiento del sistema minero obedeció, ante todo, a lógicas más globales, que van más allá de una cultura consumidora hispanoamericana” (p. 800).

Considero que lo que aquí se juega no es tanto que subestime el contexto sino la validez de mi enfoque en los actores, su agencia y sus prácticas, en fin, la eterna pregunta por la relación entre actores y estructuras. Yo insisto en que fueron las nuevas élites americanas las que hicieron fluir la plata, movidos por sus propios intereses. Pero asimismo creo que es necesario seguir discutiendo si estas élites no sólo siguieron fuerzas estructurales mayores y, a un nivel más concreto, si no fueron sólo agentes de intereses externos, en fin, si no fueron élites dependientes, aunque exitosas, como existen en todos los contextos coloniales o semicoloniales. Como tal, no se podrían considerar como representantes de un polo del desarrollo. 
Es verdad que todo lo que describo se inserta en un contexto o en una lógica mayor, ya instalada en el momento de la conquista, impuesta a los territorios americanos desde afuera y ejecutada por los que yo llamo "las nuevas élites americanas". Sin profundizar demasiado, en este contexto o lógica habría que tomar en cuenta la formación de imperios que caracteriza toda la época y, sobre todo, el comercio de larga distancia que estaba prosperando desde hacía siglos y se caracterizaba, entre otras cosas, por un sistema monetario basado en metales preciosos y por el flujo de estos metales hacia el oriente para su intercambio por mercancías manufactureras. La América española fue vinculada a este sistema comercial como su nueva extensión occidental, y sus nuevas élites no hicieron otra cosa que aprovechar las posibilidades que se les ofrecieron, pues esto era su función. Considerando todo esto, se explica el papel de la plata americana en el mundo de la globalización temprana y entendemos por qué el modelo minero les funcionaba a los empresarios mineros y comerciales, pero aún no sabemos por qué mecanismos concretos salió la plata.

Hay dos reflexiones que me persuaden a considerar la América española como polo de la globalización temprana, a pesar de su dependencia del contexto estructural en que se ve insertada. La primera reflexión es general. Es que vale la pena preguntarse si había alguien que pudiera actuar de forma realmente independiente de la lógica imperante o con la suficiente fuerza para transformarla profundamente. Diría que en mi época también los europeos, los musulmanes y los chinos sólo aplicaban las reglas del sistema vigente intentando sacarle provecho. En el fondo estamos frente al simple hecho de que tanto en China como en Europa nunca se tomó en consideración renunciar a la importación de plata mayoritariamente americana, y a su vez en América nunca se pensó en renunciar a la minería. Pues en China y en Europa se necesitaba la plata y en América se necesitaban las mercancías del Viejo Mundo. Sería arbitrario determinar quién, en este momento, dependía de quién. 
La otra reflexión, más concreta, nos lleva a observar que los americanos sí lograron controlar en gran medida su participación en los circuitos transcontinentales. Había sólo una fuerza que podía hasta cierto grado imponerles las reglas del juego, y esto era la metrópolis española, pero lograron reservarse suficiente autonomía para manejar la situación a su favor, por lo menos hasta el último cuarto del siglo XviII, cuando los reformadores borbónicos realizaron grandes esfuerzos parar quitarles esta autonomía. Obviamente, la llegada masiva de metales preciosos le vino muy bien a la corona, siempre necesitada de dinero. Desde los inicios del dominio español en América, vigilaba la navegación y el comercio, creaba y defendía monopolios, otorgaba privilegios y cobraba impuestos. Pero fueron los intereses hispanoamericanos los que desencadenaron estos flujos, y no la necesidad de los monarcas ni tampoco lo fue la demanda china; y la forma del intercambio, a nivel de las reglas y mucho más a nivel de las prácticas, favorecía considerablemente a los americanos. Un buen ejemplo serían los peruleros, a los que en el libro no menciono explícitamente, lo que Bonialian (pp. 797-798), con toda razón, echa de menos, aduciendo que los "llamados peruleros o los grandes comerciantes de la ciudad de México se convierten en mediadores globales independientes, con intereses propios, con plena división de invertir sus caudales en la compra de bienes en las islas Filipinas, en Cantón, en Sevilla, en Génova, en Ámsterdam, etcétera. En definitiva, son actores sociales en movimiento que no están sujetos a los intereses ni a los propósitos de los estados y corporaciones europeas”.

Admito que, de esta manera, discretamente he regresado a los actores, y esquivado la cuestión de si se puede entender una dinámica histórica de esta forma, y si no hay que buscar fuerzas estructurales que determinan el desarrollo histórico. Yo no pretendo poder contestar esta pregunta. En todo caso, no es mi intención sustituir un enfoque por el otro. Creo más bien que hay que verlos como complementarios. Pues, las estructuras no 
realizan acciones por sí mismas, sino que siempre necesitan agentes que actúen conforme a sus lógicas, las aprovechen y las reproduzcan. Pero al cumplir con esta función los agentes las manipulan o renuevan; muestran agencia y se convierten en actores. Aun si suponemos que la agencia está totalmente determinada por las estructuras (lo que yo no hago), vale la pena investigar las ideas, estrategias y prácticas de los actores, porque permiten conocer la articulación y la naturaleza de las fuerzas, reglas y normas a las que obedecen. Por lo tanto, sigo convencido que mi hipótesis puede aportar a la comprensión del funcionamiento de la globalización temprana, pero tampoco pretendo dar la explicación definitiva. Si hubiera llegado a tal explicación, sería el fin de la investigación histórica o, por lo menos, de este debate. Por suerte, aún no la he alcanzado. 
